\title{
Protective effects of miR-155-5p silencing on IFN- $\gamma$-induced apoptosis and inflammation in salivary gland epithelial cells
}

\author{
JINGLI ZHANG ${ }^{1}$, LINGLING ZHU ${ }^{2}$, HONG SHI ${ }^{1}$ and HUIZHE ZHENG ${ }^{3,4}$ \\ Departments of ${ }^{1}$ Rheumatology and Immunology, ${ }^{2}$ Hematology and ${ }^{3}$ Pathology; ${ }^{4}$ Key Laboratory of \\ Tumor Prevention and Treatment of Heilongjiang Province, Hongqi Hospital Affiliated to \\ Mudanjiang Medical University, Mudanjiang, Heilongjiang 157011, P.R. China
}

Received August 12, 2020; Accepted January 8, 2021

DOI: $10.3892 / \mathrm{etm} .2021 .10314$

\begin{abstract}
Previous studies have demonstrated that microRNAs (miRNAs/miRs) serve a vital role in the pathogenesis of Sjögren's syndrome (SS). The present study aimed to investigate the role of miR-155-5p in SS and determine its underlying molecular mechanism. An inflammatory lesion model was established by stimulating salivary gland epithelial cells (SGECs) with interferon- $\gamma($ IFN- $\gamma$ ). The apoptosis of SGECs was measured by using flow cytometry. Levels of proinflammatory factors were detected by reverse transcription-quantitative PCR and ELISA, respectively. Immunofluorescence was used for p65 staining. Dual-luciferase reporter assay was performed to verify the interaction between miR-155-5p and arrestin $\beta 2$ (ARRB2). The protein levels in the NF- $\kappa \mathrm{B}$ signaling pathway were assessed by western blotting. The results of the present study demonstrated that treatment with IFN- $\gamma$ increased miR-155-5p expression, in addition to inducing apoptosis and inflammation in SGECs. Furthermore, overexpression of miR-155-5p promoted IFN- $\gamma$-induced apoptosis and inflammation in SGECs. Overexpression of miR-155-5p also increased Bax protein expression, enzyme activities of caspase 3 and caspase 9, release of inflammatory cytokines interleukin- 6 and tumor necrosis factor- $\alpha$, and decreased Bcl-2 protein expression in IFN- $\gamma$-treated SGECs. By contrast, all of the effects aforementioned were reversed following miR-155-5p knockdown. These results demonstrated that miR-155-5p activated the NF- $\kappa B$ signaling pathway, where treatment with the NF- $\kappa B$ inhibitor,pyrrolidine dithiocarbamate,reversed the effects of miR-155-5p overexpression on the inflammatory factors in IFN- $\gamma$-induced SGECs. miR-155-5p was demonstrated to target
\end{abstract}

Correspondence to: Miss Huizhe Zheng, Department of Pathology, Hongqi Hospital Affiliated to Mudanjiang Medical University, 5 Tongxiang Road, Mudanjiang, Heilongjiang 157011, P.R. China

E-mail: zhz820123@163.com

Key words: Sjögren's syndrome, apoptosis, inflammation, microRNA-155-5p, arrestin $\beta 2$
ARRB2 and negatively regulated its expression levels, such that overexpression of ARRB 2 reversed the effects of miR-155-5p overexpression on the inflammatory response, apoptosis and the NF- $\mathrm{kB}$ signaling pathway in IFN- $\gamma$-treated SGECs. Collectively, results from the present study suggest that miR-155-5p may activate the NF- $\kappa \mathrm{B}$ signaling pathway by negatively regulating ARRB2 to promote salivary gland damage during SS pathogenesis. This suggests that miR-155-5p may serve to be a potential target for the treatment of SS.

\section{Introduction}

Sjogren's syndrome (SS) is a common systemic autoimmune disease of exocrine glands, particularly the salivary glands (1). Dry mouth caused by salivary gland dysfunction is one of the typical features of SS (2). The pathogenesis and etiology of SS remain unclear, since complex elements, including genes and the environment, have been reported to contribute to the development of this disease $(3,4)$. The inflammatory process of salivary glands is a common feature in patients with SS (5), where inflammation is associated with the persistence of interferon (IFN) signaling (6).

MicroRNAs (miRNAs/miRs) bind to target transcripts to suppress translation (7). Previous studies have demonstrated that miRNAs can regulate several biological processes, such as the innate immune response $(8,9)$. miR-155-5p has multiple functions, including the regulation of tumor development (10), immune regulation (11) and oxidative stress (12). Furthermore, due to its notable regulatory effect on the immune system, miR-155-5p is closely associated with a variety of immune-related diseases $(13,14)$, including during rheumatoid arthritis (15), systemic lupus erythematosus (16) and SS $(2,17,18)$. It has been previously reported that miR-155-5p expression is markedly elevated in the peripheral mononuclear cells of patients with primary SS (19). However, the function of miR-155-5p in SS remains unclear, where its potential effect on salivary glands damaged by SS has not been reported previously.

Arrestin $\beta 2$ (ARRB2) is a scaffolding protein of the arrestin family, which exerts multiple functions, including promoting angiogenesis, alleviating neuropathic pain and modulating the sensitivity of cancer cells to chemotherapy drugs (20-22). Previous studies have demonstrated that ARRB2 also exhibits 
anti-inflammatory effects in some inflammatory diseases, such as colitis and sepsis (23-25). In addition, ARRB2 has been reported to inhibit $\mathrm{NF}-\kappa \mathrm{B}$ signaling in septic and lipopolysaccharide-treated mice $(23,26)$. Previous studies have demonstrated that $\mathrm{NF}-\kappa \mathrm{B}$ serve a promoting role in $\mathrm{SS}$ and its complications $(27,28)$. Therefore, based on these previous findings aforementioned, the present study hypothesized that miR-155-5p may participate in SS-induced salivary gland damage by targeting ARRB2.

\section{Materials and methods}

Isolation, transfection and treatment of salivary gland epithelial cells (SGECs). The present study was approved by the Ethics Committee of Hongqi Hospital Affiliated to Mudanjiang Medical University (Mudanjiang, China) and performed in accordance with the Guidelines for the Care and Use of Laboratory Animals (29).

BALB/c mice, aged 7-8 weeks, weighted 20 2 g ( $n=30$; 15 male and female) were purchased from Beijing Huafukang Biotechnology Co., Ltd. (http://www.hfkbio.com/). The housing conditions of the mice were: 12-h light/dark cycle, $25 \pm 1^{\circ} \mathrm{C}$, and $45-55 \%$ humidity. All the mice were free access to food and water. Mice were euthanized by an intraperitoneal injection of sodium pentobarbital $(200 \mathrm{mg} / \mathrm{kg})$. In total, five mice were randomly selected from the 30 mice and the salivary glands were collected from the parotid, submandibular and sublingual glands. In accordance with previous research, SGECs were extracted from the salivary glands of five mice and pooled (30). Briefly, the salivary glands were washed 2-3 times with PBS. Tissue samples were minced into fragments $\left(1-2 \mathrm{~mm}^{3}\right)$ and cultured in a petri dish. Following incubation for $2 \mathrm{~h}$ at $37^{\circ} \mathrm{C}, \mathrm{DMEM} / \mathrm{F} 12$ complete medium (Procell Life Science \& Technology Co., Ltd.) was added to the petri dish and the fragments were further incubated for $72 \mathrm{~h}$ at $37^{\circ} \mathrm{C}$ in $5 \% \mathrm{CO}_{2}$ and saturated humidity. The culture medium was replaced every 3 days until the cell density reached $\sim 80 \%$. The isolated SGECs were cultured in DMEM/nutrient mixture F-12 medium (Procell Life Science \& Technology Co., Ltd.) supplemented with streptomycin $(100 \mu \mathrm{g} / \mathrm{ml})$, epidermal growth factor $(10 \mathrm{ng} / \mathrm{ml}$; Sino Biological), insulin $(0.5 \mathrm{mg} / \mathrm{ml}$; Shenyang Bying Biotechnology Co., Ltd.), hydrocortisone (0.4 mg/ml; Shanghai Aladdin Biochemical Technology Co., Ltd.) and FBS (3\%; Biological Industries), at $37^{\circ} \mathrm{C}$ in $5 \% \mathrm{CO}_{2}$. SGECs were identified via immunocytochemistry staining of cytokeratin (CK) 7, CK8 and CK19 $(31,32)$.

Transfection. Negative control (NC)/miR-155-5p agomir ( $25 \mathrm{nmol} / \mathrm{l}$; Shanghai GenePharma Co.,Ltd.) or NC/miR-155-5p antagomir ( $25 \mathrm{nmol} / \mathrm{l}$; Shanghai GenePharma Co., Ltd.) were transfected into SGECs for $24 \mathrm{~h}$ at $37^{\circ} \mathrm{C}$ using Lipofectamine ${ }^{\circledR}$ 3000 reagent ( $5 \mu \mathrm{l}$; Invitrogen; Thermo Fisher Scientific, Inc.). SGECs were treated with IFN- $\gamma(10 \mathrm{ng} / \mathrm{ml}$, Sino Biological https://www.sinobiological.com/) for $12 \mathrm{~h}$ at $37^{\circ} \mathrm{C}$ to induce inflammation as previously described (30). For drug inhibition, SGECs were transfected with miR-155-5p agomir/agomir NC for $24 \mathrm{~h}$ at $37^{\circ} \mathrm{C}$, followed by treatment with IFN- $\gamma(10 \mathrm{ng} / \mathrm{ml})$ and pyrrolidine dithiocarbamate (PDTC, $100 \mathrm{uM}$; Shanghai Aladdin Biochemical Technology Co., Ltd.) for $12 \mathrm{~h}$. For rescue experiments, ARRB2 overexpression vector (pcDNA3.1;
$121.3 \mathrm{ng} / \mu 1$, Genscript) or pcDNA3.1 vector $(154.6 \mathrm{ng} / \mu 1$, Genscript) and miR-155-5p agomir were co-transfected into the SGECs. These concentrations of ARRB2 overexpression vector and its $\mathrm{NC}$ were used for co-transfection. Following transfection for $24 \mathrm{~h}$ at $37^{\circ} \mathrm{C}$, the cells were treated with IFN- $\gamma(10 \mathrm{ng} / \mathrm{ml})$ for $12 \mathrm{~h}$. The sequences of the miR-155-5p agomir/NC agomir and miR-155-5p antagomir/NC antagomir were: miR-155-5p agomir sense, 5'-UUAAUGCUAAUUGUG AUAGGGGU-3' and antisense, 5'-CCCUAUCACAAUUAG CAUUAAUU-3'; NC agomir sense, 5'-UUCUCCGAACGU GUCACGUTT-3' and antisense, 5'-ACGUGACACGUUCGG AGAATT-3'; miR-155-5p antagomir, 5'-ACCCCUAUCACA AUUAGCAUUAA-3' and NC antagomir, 5'-CAGUACUUU UGUGUAGUACAA-3'.

Immunocytochemistry. SGECs $\left(3 \times 10^{4}\right.$ cells each well) in 12 -well plate were fixed in $4 \%$ paraformaldehyde for $15 \mathrm{~min}$ at room temperature and subsequently incubated with $3 \%$ $\mathrm{H}_{2} \mathrm{O}_{2}$ for $15 \mathrm{~min}$ at room temperature to inhibit endogenous peroxidase activity. No antigen retrieval was performed before this. Cells were blocked in $100 \%$ normal goat serum (Beijing Solarbio Science \& Technology Co., Ltd.) for $15 \mathrm{~min}$ at room temperature and incubated with primary antibodies against CK7 (1:200, cat. no. A4765; ABclonal Biotech Co., Ltd.), CK8 (1:200, cat. no. 17514-1-AP; ProteinTech Group, Inc.) and CK19 (1:200, cat. no. A19040; ABclonal Biotech Co., Ltd.) overnight at $4^{\circ} \mathrm{C}$. Following the primary antibody incubation, cells were incubated with horseradish peroxidase (HRP)-conjugated goat anti-rabbit $\lg$ (1:500, cat. no. 31460; Thermo Fisher Scientific, Inc) for $2 \mathrm{~h}$ at $37^{\circ} \mathrm{C}$ (Thermo Fisher Scientific, Inc.). DAB and hematoxylin (both purchased from Beijing Solarbio Science \& Technology Co., Ltd.) were used for color development (5 min at room temperature) and counterstaining ( $5 \mathrm{~min}$ at room temperature), respectively. The slides were observed under a light microscope (magnification, $\mathrm{x} 400$; Olympus Corporation).

Reverse transcription-quantitative PCR (RT-qPCR). Total RNA was extracted from IFN- $\gamma$-treated SGECs using TRIPure reagent (cat. no. RP1001; BioTeke Corporation,) and reverse transcribed into cDNA using M-MLV reverse transcriptase (cat. no. PR6502; BioTeke Corporation,), dNTPs (Beijing Solarbio Science \& Technology Co., Ltd.), and primers (Genscript, random hexamers and poly-A were used). The temperature protocol was used for reverse transcription for miR-155-5p: $37^{\circ} \mathrm{C}$ for $30 \mathrm{~min}, 42^{\circ} \mathrm{C}$ for $30 \mathrm{~min}$ and $70^{\circ} \mathrm{C}$ for $10 \mathrm{~min}$. For interleukin-6 (IL-6), tumor necrosis factor- $\alpha$ (TNF- $\alpha$ ), ARRB2 and $\beta$-actin, the temperature protocol was: $25^{\circ} \mathrm{C}$ for $10 \mathrm{~min}, 42^{\circ} \mathrm{C}$ for $50 \mathrm{~min}$ and $80^{\circ} \mathrm{C}$ for $10 \mathrm{~min}$. The qPCR was performed using $\mathrm{SYBR}^{\circledR}$ Green I nucleic acid gel stain (cat. no. S9430; Sigma-Aldrich; Merck KGaA) and 2X Power Taq PCR Master Mix (cat. no. PR1702, BioTeke Corporation). The temperature protocol was used for qPCR for miR-155-5p was the following: Initial denaturation at $94^{\circ} \mathrm{C}$ for $4 \mathrm{~min}$, followed by 40 cycles of $94^{\circ} \mathrm{C}$ for $15 \mathrm{sec}, 60^{\circ} \mathrm{C}$ for $20 \mathrm{sec}$ and $72^{\circ} \mathrm{C}$ for $15 \mathrm{sec}$. For IL- 6 , TNF- $\alpha$, ARRB 2 and $\beta$-actin, the thermocycling conditions were the following: Initial denaturation at $94^{\circ} \mathrm{C}$ for $5 \mathrm{~min}$, followed by 40 cycles of $94^{\circ} \mathrm{C}$ for $15 \mathrm{sec}$, $60^{\circ} \mathrm{C}$ for $25 \mathrm{sec}$ and $72^{\circ} \mathrm{C}$ for $30 \mathrm{sec}$. The following primer sequences were used for qPCR: miR-155-5p forward, 5'-TTA ATGCTAATTGTGATAGGGGT-3' and reverse, 5'-GCAGGG 
TCCGAGGTATTC-3'; 5S rRNA forward, 5'-CTAAAGATT TCCGTGGAGAG-3' and reverse, 5'-TGGTGCAGGGTCCGA GGTAT-3'; IL-6 forward, 5'-ATGGCAATTCTGATT GTATG-3' and reverse, 5'-GACTCTGGCTTTGTC TTTCT-3'; TNF- $\alpha$ forward, 5'-CAGGCGGTGCCTATG TCTCA-3' and reverse, 5'-GCTCCTCCACTTGGTGGTTT-3'; ARRB2 forward, 5'-CCATTGTGAAGGAGGGAG-3' and reverse, 5'-GCATTAGGACGAAGGGTAG-3' and $\beta$-actin forward, 5'-CTGTGCCCATCTACGAGGGCTAT-3' and reverse, 5'-TTTGATGTCACGCACGATTTCC-3'. Relative expression levels were calculated using the $2^{-\Delta \Delta C q}$ method (33) and normalized to the internal reference gene $\beta$-actin. 5S rRNA served as the internal control for miRNA expression.

Cell Counting Kit-8 (CCK-8) assay. CCK-8 assay was performed to assess cell viability. SGECs were seeded into 96-well plates $\left(3 \times 10^{3}\right.$ cells each well). Following transfection for $24 \mathrm{~h}$ at $37^{\circ} \mathrm{C}$, cells were incubated with CCK-8 solution for $1 \mathrm{~h}$ following the manufacturer's protocols at $37^{\circ} \mathrm{C}(10 \mu \mathrm{l}$ each well; Sigma-Aldrich, Merck KGaA) before viability was subsequently analyzed at a wavelength of $450 \mathrm{~nm}$, using a microplate reader.

Apoptosis analysis. Early and late apoptotic cells were assessed using flow cytometry. Cells were seeded into six-well plates at a density of $1 \times 10^{5}$ cells/well. Following transfection and treatment, apoptotic cells were analyzed. Briefly, cells in each group were collected and resuspended with $195 \mu \mathrm{l}$ Annexin V-FITC (Beyotime Institute of Biotechnology). Cells $\left(1 \times 10^{5}\right)$ were subsequently treated with $5 \mu 1$ Annexin V-FITC and $10 \mu \mathrm{l}$ propidium iodide (both purchased from Beyotime Institute of Biotechnology) for $15 \mathrm{~min}$ at room temperature. Apoptotic cells were subsequently detected by flow cytometer (NovoCyte; ACEA Bioscience, Inc.) and analyzed by NovoExpress (version 1.2.5; ACEA Biosciences, Inc.).

Immunofluorescence staining. Cell slides were fixed with $4 \%$ paraformaldehyde for $15 \mathrm{~min}$ at room temperature and then incubated with $0.1 \%$ Triton X-100 for $30 \mathrm{~min}$ at room temperature. After blocking with $100 \%$ normal goat serum (Beijing Solarbio Science \& Technology Co., Ltd.) for $15 \mathrm{~min}$ at room temperature, the cell slides were incubated with the anti-p65 antibody (1:200; total non-phosphorylated version; cat. no. 10745-1-AP; ProteinTech Group, Inc.) overnight at $4^{\circ} \mathrm{C}$. After the primary antibody incubation, cells were treated with Cy3-labeled goat anti-rabbit IgG (1:200, cat. no. A0516, Beyotime Institute of Biotechnology) for $60 \mathrm{~min}$ at room temperature. After staining the nucleus with DAPI (cat. no. C1002; Beyotime Institute of Biotechnology) at room temperature, slides were analyzed with a fluorescence microscope (magnification, $\mathrm{x} 400$; Olympus Corporation).

Western blotting. Total protein was extracted using RIPA lysis buffer (Beyotime Institute of Biotechnology). Cytoplasmic protein and nuclear protein were extracted using a nuclear protein extraction kit (cat. no. P0027; Beyotime Institute of Biotechnology). Bicinchoninic acid protein assay kit was used to measure the protein concentration. Equal amounts of protein $(20-40 \mu \mathrm{g})$ were separated via SDS-PAGE (10 and $12 \%$ gel). The separated proteins were subsequently transferred onto PVDF membranes (EMD Millipore) and blocked with $5 \%$ non-fat milk for $1 \mathrm{~h}$ at room temperature. The membranes were incubated with primary antibodies against Bcl-2 (1:1,000; cat. no. A19693; ABclonal Biotech Co., Ltd.), Bax (1:1,000; cat. no. A19684; ABclonal

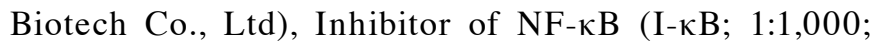
cat. no. A11397; ABclonal Biotech Co., Ltd.), phosphorylated

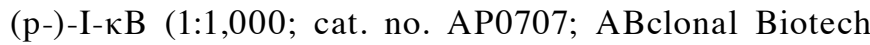
Co., Ltd.), NF-кB p65 (1:1,000; cat. no. AF5006; Affinity Biosciences), ARRB2 (1:1,000; cat. no. A1171; ABclonal Biotech Co., Ltd.), Histone H3 (1:2,000; cat. no. AM8433; Abgent Inc.) and $\beta$-actin (1:1,000; cat. no. sc-47778; Santa Cruz Technology, Inc.) overnight at $4{ }^{\circ} \mathrm{C}$. Following primary antibody incubation, membranes were incubated with HRP-conjugated anti-rabbit/mouse $\operatorname{lgG}$ (1:5,000; cat. nos. A0208 and A0216; Beyotime Institute of Biotechnology) at room temperature for $30 \mathrm{~min}$. Proteins bands were visualized using an enhanced chemiluminescence reagent solution (Beyotime Institute of Biotechnology) and analyzed using a Gel-Pro-Analyzer (version 4.0; Beijing Liuyi Biotechnology, Inc.).

Caspase-3 and -9 activities. After the cells were harvested and lysed, caspase-3 detection kit (cat. no. C1116; Beyotime Institute of Biotechnology) was used to detect caspase-3 activity in the lysates, whilst caspase-9 activity was measured using a caspase-9 detection kit (cat. no. BC3890; Beijing Solarbio Science \& Technology Co., Ltd.). Caspase-3 and -9 activities were subsequently analyzed at a wavelength of $405 \mathrm{~nm}$ detected using a microplate reader (BioTek Instruments, Inc.).

ELISA. The ELISA kits (Wuhan Boster Biological Technology, Ltd.), were used to detect the expression levels of IL-6 (cat. no. EK0411) and TNF- $\alpha$ (cat. no. EK0527) in cell culture supernatant, according to the manufacturer's protocols. Tetramethylbenzidine (TMB) substrate solution (Wuhan Boster Biological Technology, Ltd.) was used to incubate the samples for $20 \mathrm{~min}$ at $37^{\circ} \mathrm{C}$ in the dark. TMB stop solution (Wuhan Boster Biological Technology, Ltd.) was then used to suspend the color reaction. A microplate reader (BioTek Instruments, Inc.) was used to obtain the optical density value at a wavelength of $450 \mathrm{~nm}$. The lower detection limit of the ELISA kits was $15.6 \mathrm{pg} / \mathrm{ml}$.

Dual-luciferase reporter assay. The binding sites between miR-155-5p and ARRB2 were predicted using TargetScan 7.2 (http://www.targetscan.org/vert_72). Briefly, the species was 'Human', following which the microRNA name 'miR-155-5p' was typed in and the 'submit' button was clicked. A number of genes potentially targeted by miR-155-5p can then be obtained. After searching for ARRB2, the 'Sites in UTR' button was clicked to obtain the targeted binding sequence between miR-155-5p and ARRB2. The association between miR-155-5p and ARRB2 was detected using dual-luciferase reporter assay. The mirGLO-ARRB2-3'-UTR-WT and pmirGLO-ARRB2-3'-UTR-MT plasmids were synthesized by GenScript. The plasmid $(0.5 \mu \mathrm{g})$ and miR-155-5p mimic or its NC (25 pmol) were co-transfected into 293T cells at $\sim 70 \%$. The co-transfection was mediated by Lipofectamine ${ }^{\circledR}$ 3000 reagent $(9 \mu \mathrm{l}$; Invitrogen; Thermo Fisher Scientific, Inc.). Following incubation for $48 \mathrm{~h}$ at $37^{\circ} \mathrm{C}$, luciferase 
A

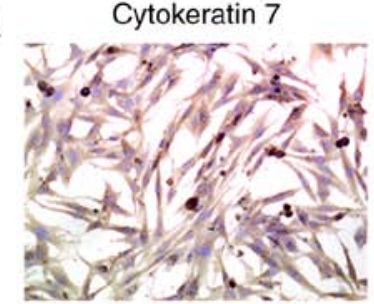

Cytokeratin 19

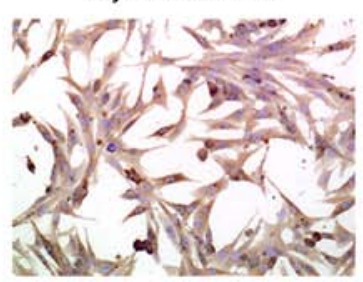

Cytokeratin 8

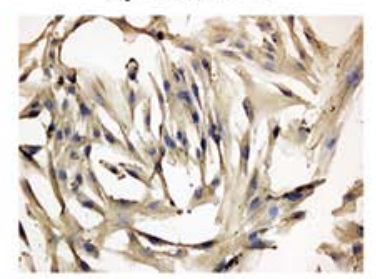

B

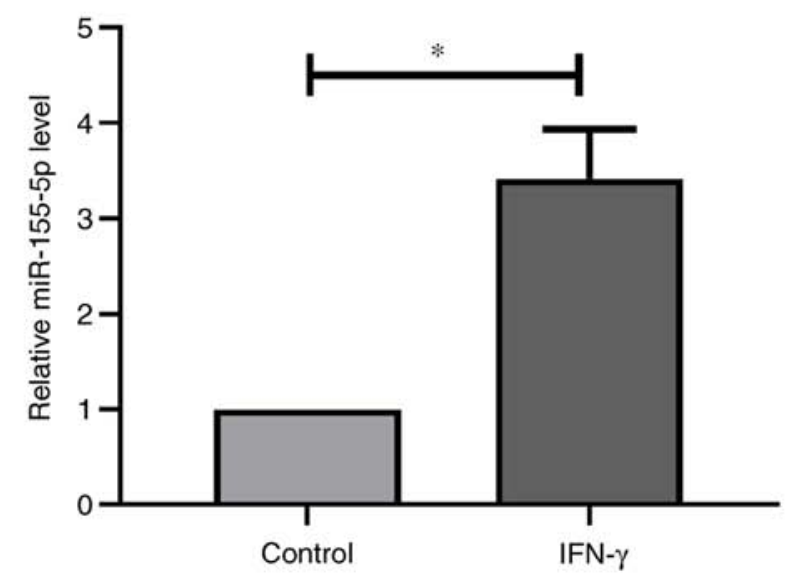

Figure 1. Expression of miR-155-5p in interferon- $\gamma$-treated SGECs. (A) Immunohistochemical staining of cytokeratin 7, cytokeratin 8 and cytokeratin 19 in SGECs (magnification, x200). (B) miR-155-5p expression was analyzed using reverse transcription-quantitative PCR. All data are presented as mean \pm SD, $\mathrm{n}=3$. ${ }^{*} \mathrm{P}<0.05$. miR, microRNA; IFN- $\gamma$, interferon- $\gamma$; SGECs, salivary gland epithelial cells.

detection kit (cat. no. E1910; Promega Corporation) was used to detect luciferase activity. The changes in luciferase activities were measured using a microplate reader (Tecan Group Ltd.). Firefly luciferase activity was normalized to that of Renilla luciferase activity.

Statistical analysis. Statistical analysis was performed using GraphPad Prism 7 software (GraphPad Software, Inc.). Data are presented as the mean \pm standard deviation. Student's unpaired t-test was used to compare differences between two groups, whilst one-way ANOVA with Tukey's post hoc test was used to compare differences between multiple groups. $\mathrm{P}<0.05$ was considered to indicate a statistically significant difference. All experiments were performed at least in triplicate.

\section{Results}

miR-155-5p expression in IFN- $\gamma$-treated SGECs. SGECs were phenotyped by immunocytochemistry staining (Fig. 1A). The results demonstrated that the isolated cells exhibited strong cytokeratin expression, including that of epithelial markers CK7, CK8 and CK19, suggesting that the isolated cells were SGECs. RT-qPCR analysis demonstrated that miR-155-5p expression was significantly increased in SGECs following treatment with IFN- $\gamma$ (Fig. 1B). Taken together, these results suggest that IFN- $\gamma$ treatment increases miR-155-5p expression.

miR-155-5p promotes IFN- $\gamma$-induced apoptosis in SGECs. The effects of miR-155-5p knockdown and overexpression on the apoptosis of IFN- $\gamma$-treated SGECs were next assessed. RT-qPCR analysis demonstrated that miR-155-5p expression was significantly upregulated following transfection with miR-155-5p agomir, but was significantly downregulated following transfection with miR-155-5p antagomir compared with that in their corresponding NCs (Fig. 2A). Transfected SGECs were subsequently treated with IFN- $\gamma(10 \mathrm{ng} / \mathrm{ml})$ for $12 \mathrm{~h}$. Treatment with IFN- $\gamma$ significantly reduced cell viability and promoted apoptosis in SGECs (Fig. 2B and C). Overexpression of miR-155-5p significantly decreased cell viability and induced apoptosis in IFN- $\gamma$-treated SGECs, whereas miR-155-5p knockdown significantly increased cell viability and inhibited apoptosis compared with those in their corresponding NCs (Fig. 2B and C). Furthermore, treatment with IFN- $\gamma$ significantly decreased Bcl-2 protein expression, but significantly increased Bax protein expression and the enzyme activity of caspase 3 and 9 in SGECs (Fig. 2D and E). Compared with those in their corresponding NCs, overexpression of miR-155-5p significantly potentiated the effect of IFN- $\gamma$ on apoptotic protein expression and caspase 3 and 9 enzyme activity, whilst opposite effects were observed following the downregulation of miR-155-5p (Fig. 2D and E). Collectively, these results suggest that the overexpression of miR-155-5p aggravates IFN- $\gamma$-induced apoptosis, whereas miR-155-5p knockdown reversed IFN- $\gamma$-induced apoptosis in SGECs.

miR-155-5p promotes IFN- $\gamma$-induced inflammation in $S G E C s$. The association between miR-155-5p and inflammation in IFN- $\gamma$-treated SGECs was assessed. Compared with those in control, treatment with IFN- $\gamma$ significantly increased the mRNA expression levels of IL-6 and TNF- $\alpha$ in SGECs, which was significantly enhanced further following overexpression of miR-155-5p (Fig. 3A). By contrast, this phenomenon was reversed by miR-155-5p knockdown (Fig. 3A). Similar results were obtained according to results from ELISA (Fig. 3B). Taken together, these results suggest that overexpression of miR-155-5p may promote IFN- $\gamma$-induced inflammation, whilst miR-155-5p knockdown may alleviate IFN- $\gamma$-induced inflammation in SGECs.

miR-155-5p activates the $N F-\kappa B$ signaling pathway in IFN- $\gamma$-treated SGECs. The effects of miR-155-5p knockdown and overexpression on the NF- $\kappa \mathrm{B}$ signaling pathway in IFN- $\gamma$-treated SGECs were next assessed. Western blot analysis demonstrated that the $\mathrm{p}-\mathrm{I}-\kappa \mathrm{B} / \mathrm{I}-\kappa \mathrm{B}$ ratio and the nuclear/cytoplasmic ratio of $\mathrm{p} 65$ were significantly increased following treatment with IFN- $\gamma$, which was significantly potentiated following the transfection with miR-155-5p 

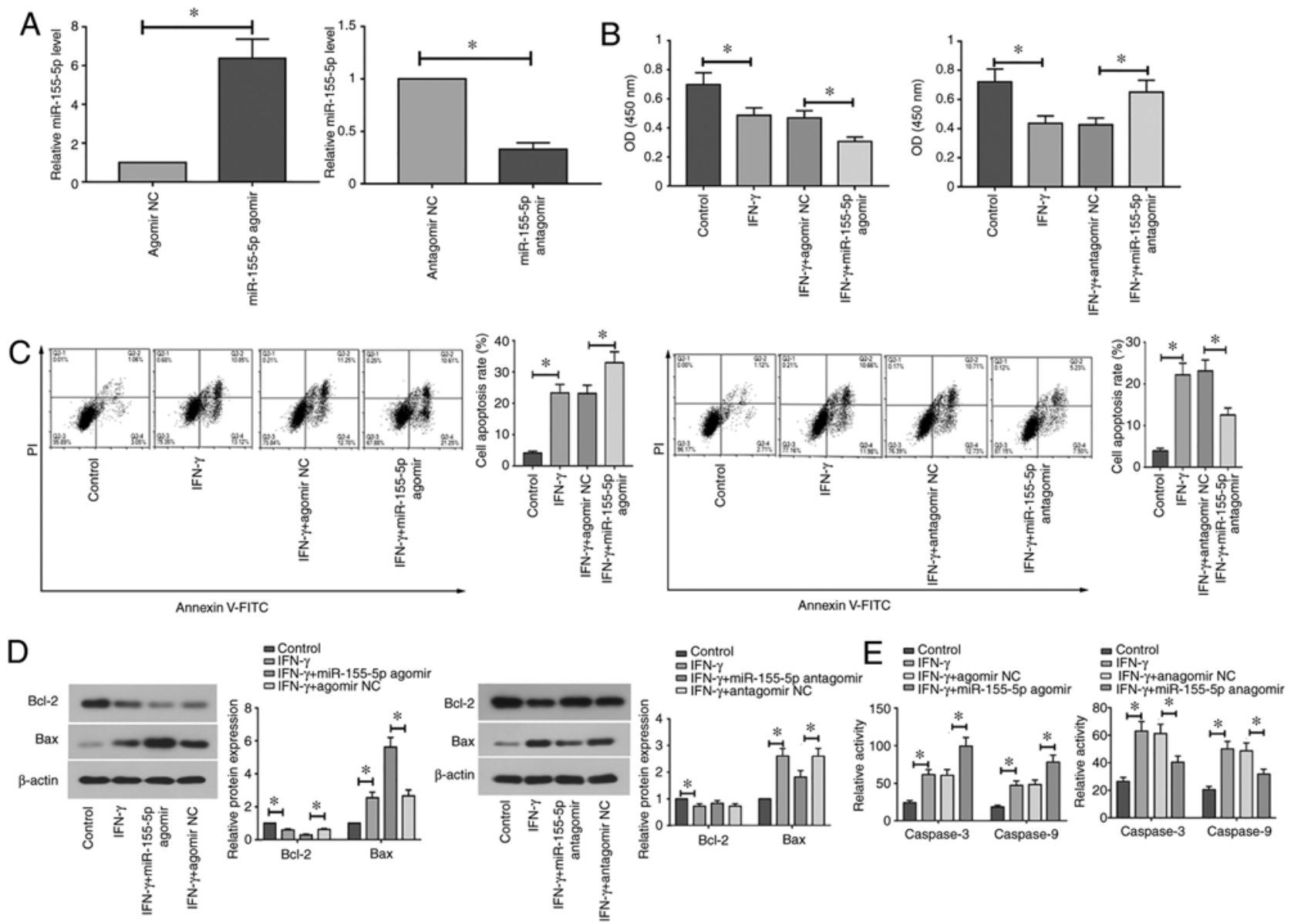

Figure 2. miR-155-5p overexpression promotes IFN- $\gamma$-induced apoptosis in SGECs. (A-E) SGECs were transfected with miR-155-5p agomir/agomir NC or miR-155-5p antagomir/antagomir NC for $24 \mathrm{~h}$, before the transfected SGECs were treated with IFN- $\gamma$ at a concentration of $10 \mathrm{ng} / \mathrm{ml}$ for $12 \mathrm{~h}$. (A) The efficiency of miR-155-5p agomir or antagomir transfection was detected by reverse transcription-quantitative PCR. (B) Cell viability of SGECs was detected by Cell Counting Kit-8 assay. (C) Early and late apoptotic cells were assessed by flow cytometry. The regions of Q2-2 + Q2-4 represent the apoptotic cells. (D) The expression of Bcl-2 and Bax was detected by western blotting. (E) Caspase-3 activity and caspase-9 activity were measured. All data were presented as mean $\pm \mathrm{SD}, \mathrm{n}=3$. ${ }^{*} \mathrm{P}<0.05$. SGECs, salivary gland epithelial cells; NC, negative control; IFN- $\gamma$, interferon- $\gamma$; miR, microRNA; OD, optical density.

agomir (Fig. 4A and B). By contrast, they were significantly reversed following transfection with miR-155-5p antagomir (Fig. 4A and B). Immunofluorescence staining demonstrated that the overexpression of miR-155-5p promoted the nuclear translocation of NF- $\kappa \mathrm{B}$ p65 (total non-phosphorylated version) in IFN- $\gamma$-treated cells, whilst miR-155-5p knockdown resulted in the opposite effect being observed (Fig. 4C). Following the transfection with miR-155-5p agomir/agomir NC, SGECs were treated with IFN- $\gamma(10 \mathrm{ng} / \mathrm{ml})$ and PDTC $(100 \mu \mathrm{M})$. The results demonstrated that the blockade of $\mathrm{NF}-\kappa \mathrm{B}$ signaling by PDTC significantly decreased the expression levels of IL-6 and TNF- $\alpha$ in miR-155-5p-overexpressed SGECs (Fig. 4D). Collectively, these results suggest that miR-155-5p overexpression aggravates IFN- $\gamma$-induced $N F-\kappa B$ signaling in SGECs.

ARRB2 is a downstream target gene of miR-155-5p. The binding sites of miR-155-5p on ARRB2 were predicted using TargetScan 7.2 (http://www.targetscan.org/vert_72), where miR-155-5p was predicted to target ARRB2 directly (Fig. 5A). Dual-luciferase reporter assay results showed that luciferase activity in miR-155-5p agomir + WT 3'UTR group was significantly decreased compared with that in the miR-155-5p agomir + MT 3'UTR and Agomir NC + WT 3'UTR groups (Fig. 5A). The association between miR-155-5p expression and ARRB2 was subsequently assessed. The results demonstrated that ARRB2 mRNA and protein expression levels were significantly inhibited in IFN- $\gamma$-treated SGECs following transfection with miR-155-5p agomir compared with those in IFN- $\gamma$-treated cells transfected with NC agomir (Fig. 5B and C). Conversely, ARRB2 mRNA and protein expression levels were significantly elevated in IFN- $\gamma$-treated SGECs following transfection with miR-155-5p antagomir compared with those in IFN- $\gamma$-treated cells transfected with NC antagomir (Fig. 5B and C). Subsequently, the ARRB2 overexpression plasmid and miR-155-5p agomir were co-transfected into SGECs before IFN- $\gamma(10 \mathrm{ng} / \mathrm{ml})$ was used to treat the transfected cells for $12 \mathrm{~h}$. The transfection efficiency of the ARRB2 plasmid into SGECs was first verified by western blotting (Fig. 5D). In the presence of both IFN- $\gamma$ and miR-155-5p mimics, overexpression of ARRB2 significantly reduced the expression levels of IL- 6 and TNF- $\alpha$ (Fig. 5E). In addition, the overexpression of ARRB2 significantly suppressed the miR-155-5p overexpression-induced apoptosis in IFN- $\gamma$-treated SGECs (Fig. 5G). Translocation of NF- $\kappa$ B p65 from the cytoplasm to the nucleus, which was 
A
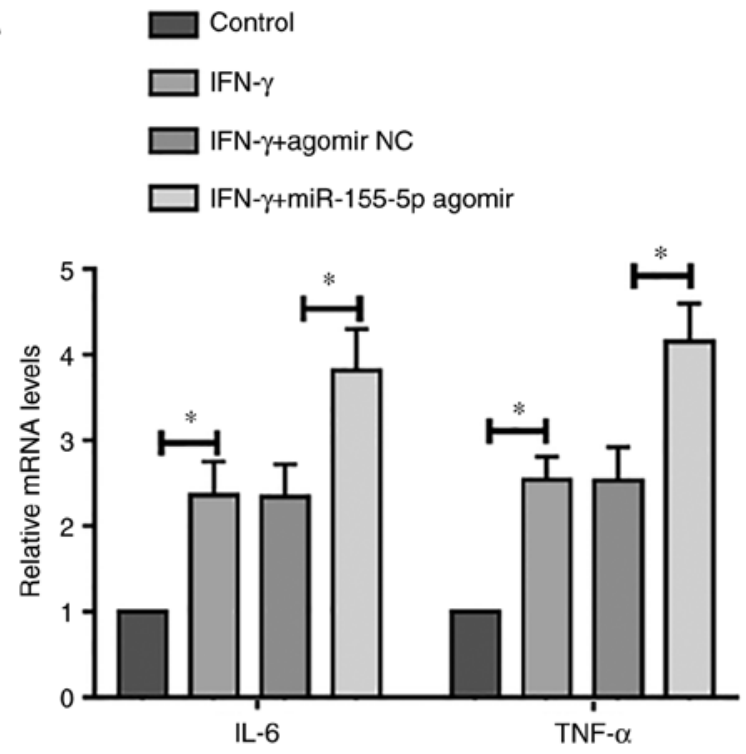

B
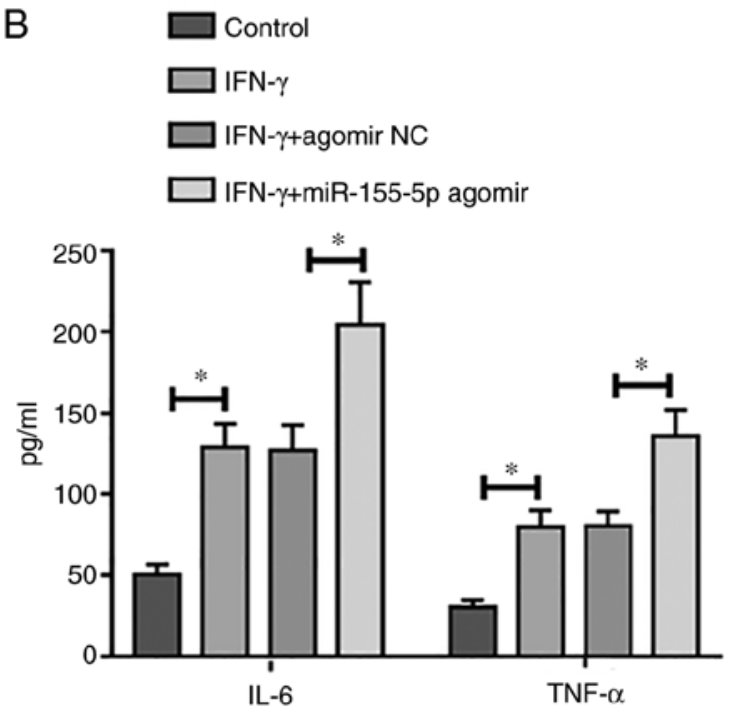

Control

IFN- $\gamma$

IFN- $\gamma+$ antagomir NC

IFN- $\gamma+$ miR-155-5p antagomir

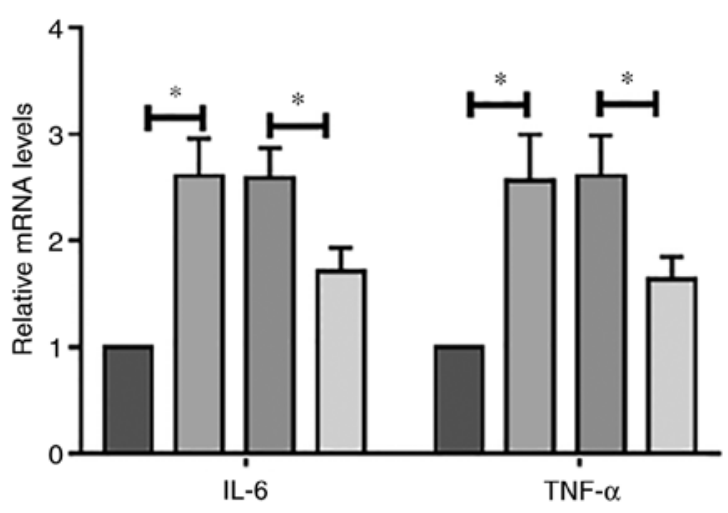

$\square$ Control

$\square$ IFN-y

$\square$ IFN- $\gamma+$ antagomir NC

$\square$ IFN- $\gamma+$ miR-155-5p antagomir

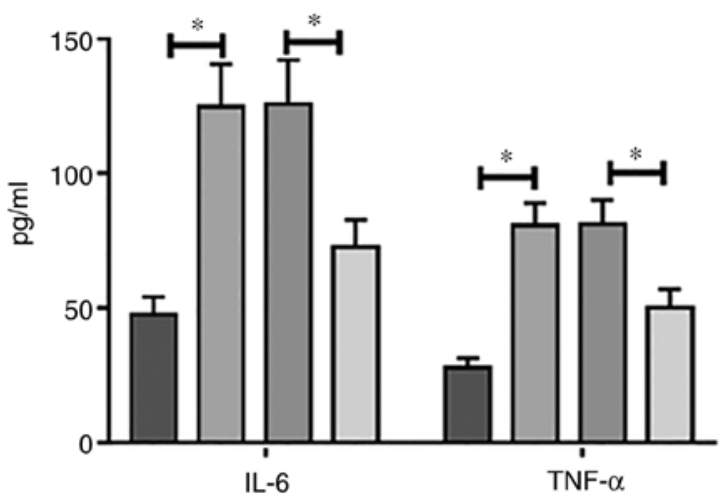

Figure 3. miR-155-5p promotes IFN- $\gamma$-induced inflammation in SGECs. (A and B) SGECs were transfected with miR-155-5p agomir/agomir NC or miR-155-5p antagomir/antagomir NC for $24 \mathrm{~h}$, before the transfected SGECs were treated with IFN- $\gamma$ at a concentration of $10 \mathrm{ng} / \mathrm{ml}$ for $12 \mathrm{~h}$. (A) IL-6 and TNF- $\alpha$ mRNA expression was assessed using reverse transcription. (B) Levels of IL-6 and TNF- $\alpha$ in cell culture supernatant were quantified using ELISA. All data were presented as mean $\pm \mathrm{SD}, \mathrm{n}=3$. "P<0.05. SGECs, salivary gland epithelial cells; IFN- $\gamma$, interferon- $\gamma$; NC, negative control; IL-6, interleukin-6; TNF- $\alpha$, tumor necrosis factor- $\alpha$.

observed to be induced by the overexpression of miR-155-5p, was also significantly abrogated following the overexpression of ARRB2 in IFN- $\gamma$-treated SGECs (Fig. 5F). Taken together, these results suggest that ARRB2 may partially or completely mediate the effects of miR-155-5p on inflammation and apoptosis in IFN- $\gamma$-treated SGECs.

\section{Discussion}

The results of the present study demonstrated that treatment with IFN- $\gamma$ increased miR-155-5p expression, such that apoptosis and inflammation in IFN- $\gamma$-treated SGECs may be induced by this increased miR-155-5p expression. Furthermore, it was demonstrated that miR-155-5p may activate NF- $\mathrm{\kappa B}$ signaling by negatively regulating ARRB2, thereby promoting salivary gland damage in SS.
SS is an autoimmune disease, particularly in the exocrine glands, such as salivary and lacrimal glands (34). However, the pathogenesis of SS remains unclear. Therefore, it is necessary to study the pathogenesis of SS and its potential therapeutic targets. It has been previously demonstrated that miRNAs can regulate in immune responses, including infection and autoimmunity $(35,36)$. Previous studies have also reported that miR-155-5p exerts an important regulatory role in the generation of humoral and cellular immune responses during infection and autoimmunity $(37,38)$.

Salivary gland damage is a common clinical symptom of SS (39). Previous studies have demonstrated that patients with SS and animal models of SS exhibit secretory dysfunction, particularly in the salivary gland epithelium $(40,41)$. In addition, inflammation and apoptosis of SGECs have also been reported to be a possible mechanism for impaired secretory function (42). 

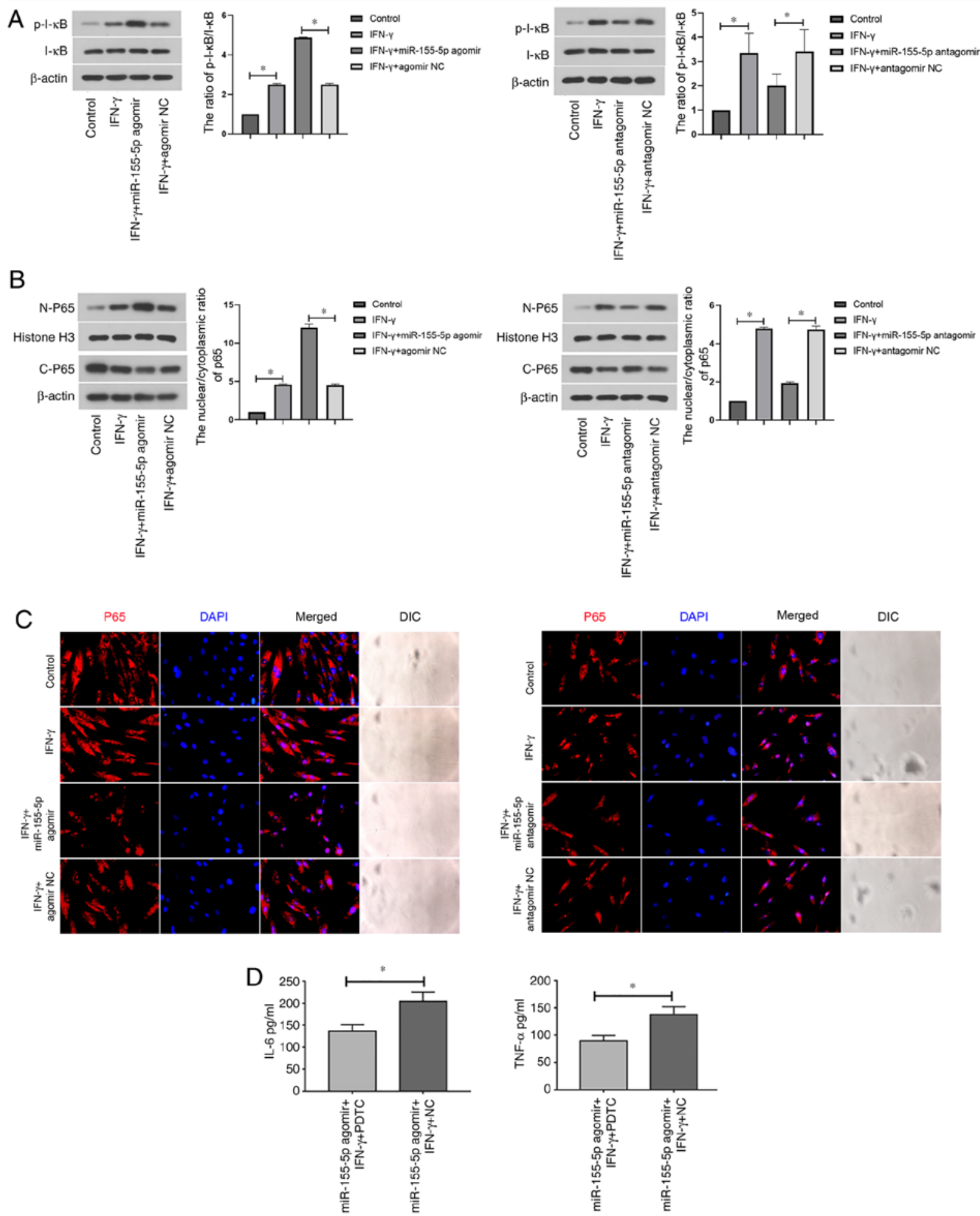

Figure 4. miR-155-5p activates the NF- $\mathrm{BB}$ signaling pathway in IFN- $\gamma$-treated SGECs. (A-C) SGECs were transfected with miR-155-5p agomir/agomir NC or miR-155-5p antagomir/antagomir NC for $24 \mathrm{~h}$, before the transfected SGECs were treated with IFN- $\gamma$ at a concentration of $10 \mathrm{ng} / \mathrm{ml}$ for $12 \mathrm{~h}$. Expression of

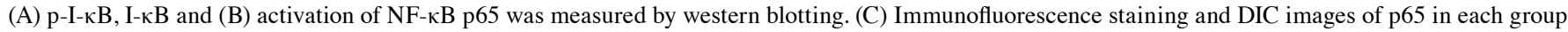
were shown (magnification, $\mathrm{x} 400$ ). (D) miR-155-5p agomir/agomir NC-transfected SGECs were treated with IFN- $\gamma(10 \mathrm{ng} / \mathrm{ml})$ and PDTC (100 $\mu \mathrm{M})$ for $12 \mathrm{~h}$, before the levels of IL- 6 and TNF- $\alpha$ were detected by ELISA. All data were presented as mean \pm SD, $n=3$. "P<0.05. SGECs, salivary gland epithelial cells; $\mathrm{n}$-, nuclear; c-, cytoplasmic; NC, negative control; IFN- $\gamma$, interferon-gamma; PDTC, pyrrolidine dithiocarbamate; IL-6, interleukin-6; TNF- $\alpha$, tumor necrosis

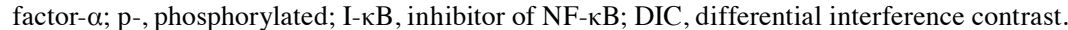

Release of proinflammatory cytokines, including TNF- $\alpha$ and IFN- $\gamma$, in the exocrine glands of patients with SS and apoptosis of SGECs significantly increases $(43,44)$. The present study investigated the effects of miR-155-5p on the apoptosis and inflammation in SGECs. Previous studies have demonstrated that miR-155-5p expression is positively associated with primary SS (19). High levels of miR-155-5p have also been reported in inflammatory lesion models, such as cerebral 
A

miR-155-5p: 3'-AUCGUAAUU-5' Wt-ARRB2 3'UTR: 5' -GGGCAUUAA-3' mt-ARRB2 3'UTR: 5'-GGCGUAAUA-3'

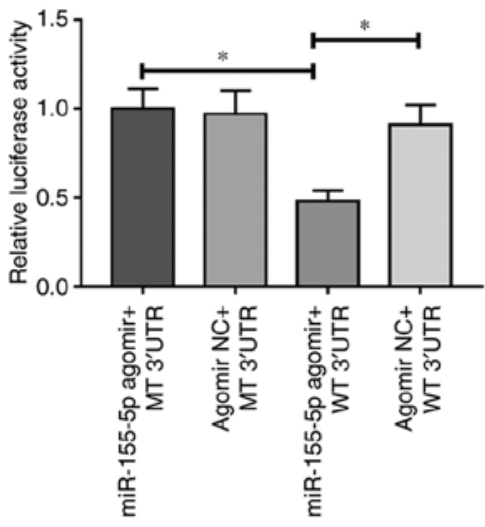

B

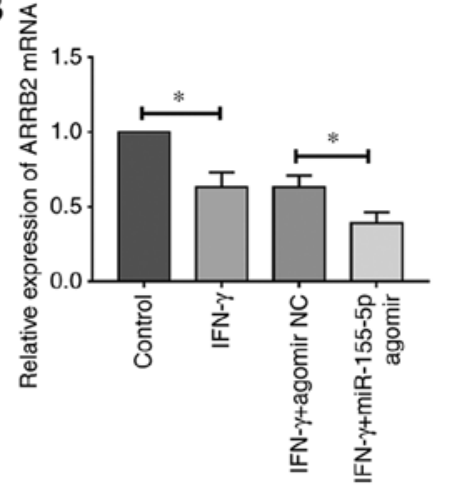

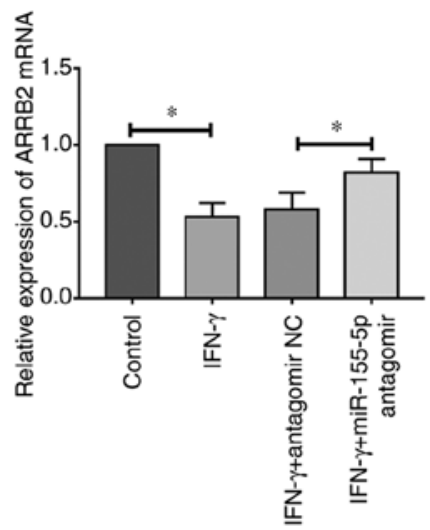

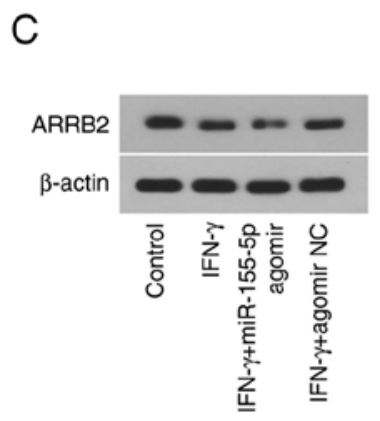

D
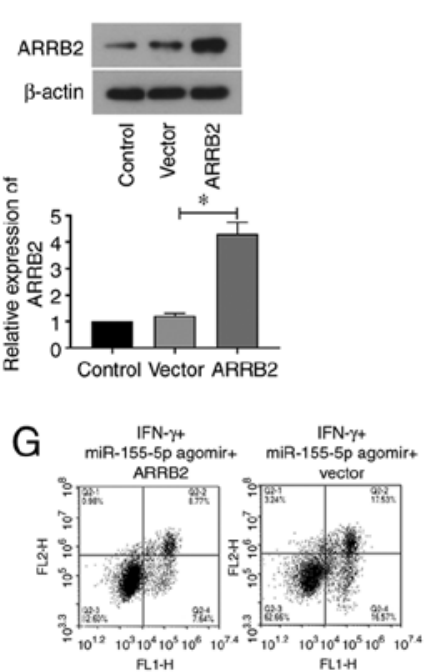

E
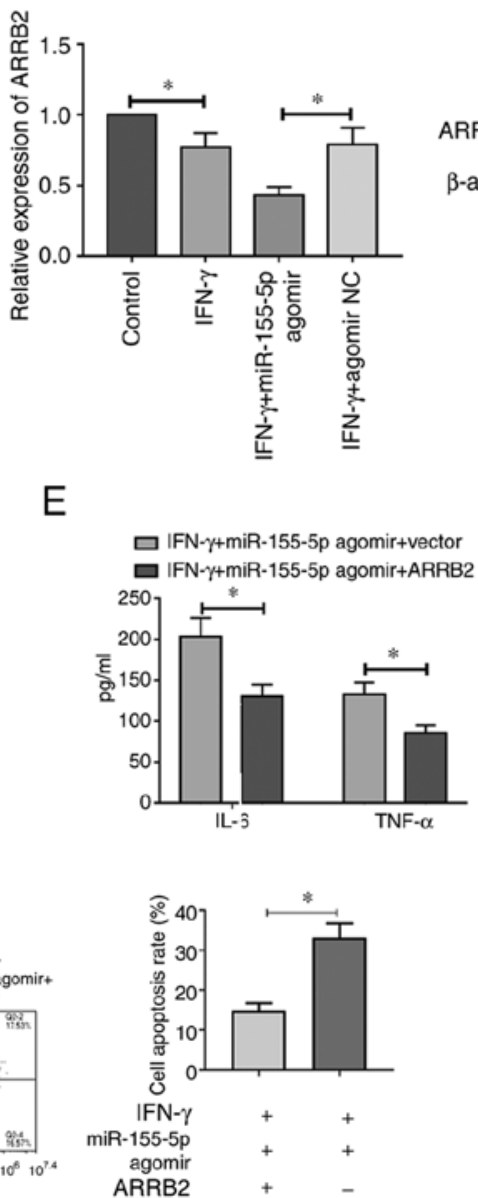
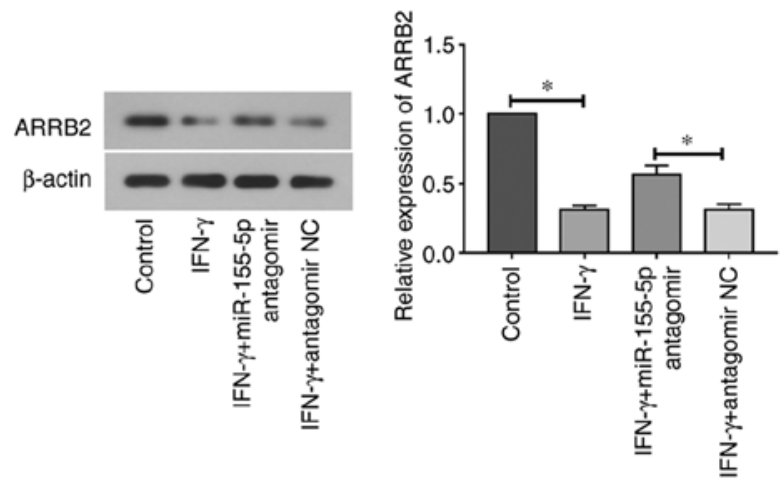

$\mathrm{F}$
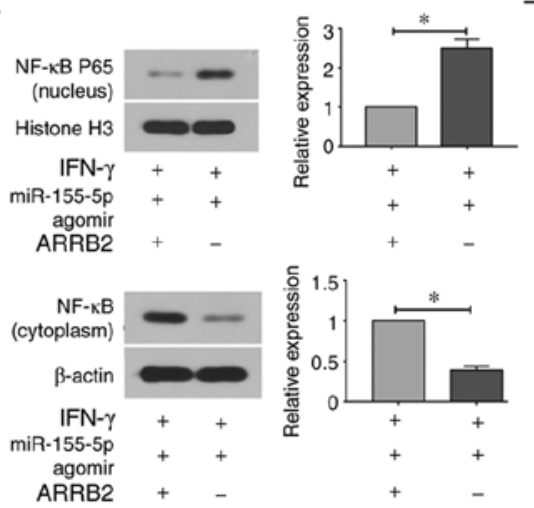

Figure 5. ARRB2 is a downstream target gene of miR-155-5p. (A) The specific binding site of miR-155-5p on ARRB2 is shown, where the interaction between miR-155-5p and ARRB2 was assessed using the dual-luciferase activity assay. (B) mRNA levels of ARRB2 in IFN- $\gamma$-treated SGECs after miR-155-5p agomir or antagomir transfection were measured using reverse transcription-quantitative PCR. (C) Protein levels of ARRB2 in IFN- $\gamma$-treated SGECs after miR-155-5p agomir or antagomir transfection were determined by western blotting. (D) Overexpression efficiency of ARRB2 in salivary gland epithelial cells was measured by western blotting. (E-G) SGECs were co-transfected with ARRB2 vector and miR-155-5p agomir before they were treated with IFN- $\gamma(10 \mathrm{ng} / \mathrm{ml})$ for $12 \mathrm{~h}$. (E) The levels of IL-6 and TNF- $\alpha$ were detected by ELISA. (F) The expression and activation of NF- $\mathrm{kB}$ p65 was measured by western blotting. (G) Both early and late apoptotic cells were assessed by flow cytometry. The regions of Q2-2 + Q2-4 represent the apoptotic cells. All data were presented as mean $\pm \mathrm{SD}, \mathrm{n}=3$. "P<0.05. ARRB2, $\beta$-arrestin 2; IFN- $\gamma$, interferon- $\gamma$; SGECs, salivary gland epithelial cells; IL-6, interleukin-6; TNF- $\alpha$, tumor necrosis factor- $\alpha$; miR, microRNA; WT, wild type; mut, mutant; UTR, untranslated region.

ischemia-reperfusion injury (45). As previously reported, an inflammatory lesion model was established in SGECs by treatment with IFN- $\gamma$, where IFN- $\gamma$-treatment increased apoptosis and IL-6 and TNF- $\alpha$ mRNA expression (30).
Results from the present study demonstrated that miR-155-5p overexpression promoted IFN- $\gamma$-induced apoptosis in SGECs, since cell viability was decreased and the apoptotic rate was increased, in addition to the increased expression levels of 
apoptosis-related proteins in miR-155-5p overexpressing cells. These results also demonstrated that miR-155-5p overexpression promoted IFN- $\gamma$-induced inflammation, which was evidenced by the increased IL- 6 and TNF- $\alpha$ levels in miR-155-5p overexpressing cells. Overall, these results suggest that miR-155-5p may exert a role in salivary gland damage during SS by promoting the inflammatory response and apoptosis of SGECs.

$\mathrm{NF}-\kappa \mathrm{B}$ is chronically active in several inflammatory autoimmune diseases, including inflammatory bowel disease (46), rheumatoid arthritis (47) and SS (48). Sisto et al (49) demonstrated that the NF- $\mathrm{BB}$ signaling pathway is activated in human SGECs derived from active primary patients with SS. Lisi et al (50) reported that activation of NF- $\mathrm{KB}$ signaling is a potentially important mechanism for SS development. Furthermore, it has been demonstrated that dysregulation of NF- $\mathrm{KB}$ in glandular epithelial cells results in Sjogren's-like features (51). Activation of NF- $\kappa \mathrm{B}$ signaling promotes inflammation and induces apoptosis of human SGECs in primary SS (52). Proinflammatory cytokines, such as IFN- $\gamma$, activate the IкB kinase complex, which phosphorylates I $\mathrm{B}$ and targets it for proteasomal degradation (53). This releases NF- $\kappa \mathrm{B}$ which, after phosphorylation, allows it to translocate into the nucleus (53). NF- $\mathrm{BB}$ either acts alone in the nucleus or with other transcription factors to induce target gene expression (53). The results of the present study demonstrated that the phosphorylation levels of I $\mathrm{KB}$ and the nuclear translocation of p65 were increased, suggesting that miR-155-5p activates $\mathrm{NF}-\mathrm{KB}$ signaling. Taken together, these results suggest that miR-155-5p may promote salivary gland damage in SS by regulating the NF- $\mathrm{KB}$ signaling pathway.

ARRB2 is a downstream target gene of miR-155-5p (54). The results of the present study verified this association. Li et al (55) demonstrated that the overexpression of ARRB2 may inhibit the release of proinflammatory cytokines and decrease experimental arthritis severity. In addition, ARRB2 has exhibited antiapoptotic effects in human endometrial cancer heterotransplants in nude mice $(56,57)$. The results of the present study demonstrated that overexpression of ARRB2 reversed the effects of miR-155-5p overexpression on the inflammatory response, apoptosis and the NF- $\mathrm{kB}$ signaling pathway in this inflammatory lesion model. ARRB2 has been previously reported to inhibit the NF- $\mathrm{NB}$ signaling pathway in a sepsis mouse model and LPS-induced liver injury $(23,26)$. Collectively, these results suggest that miR-155-5p may promote salivary gland damage in SS by negatively regulating ARRB2. Notably, miR-155-5p and IFN- $\gamma$ can influence each other, whereby the overexpression of miR-155-5p increased the production of IFN- $\gamma(58)$. IFN- $\gamma$ has been demonstrated to induce miR-155-5p expression in human dermal lymphatic endothelial cells (58-60). Results of the present study demonstrated that the treatment with IFN- $\gamma$ induced miR-155-5p expression, indicating that IFN- $\gamma$ may in part induce the apoptosis and inflammation of SGECs by regulating miR-155-5p expression.

In conclusion, functional studies in the present study demonstrated that miR-155-5p overexpression can promote IFN- $\gamma$-induced apoptosis and inflammation in SGECs. Mechanistic studies have indicated that miR-155-5p activates $\mathrm{NF}-\kappa \mathrm{B}$ signaling by negatively regulating ARRB2, thereby promoting salivary gland damage of SS. The results of the present study verified the role and the potential molecular mechanism of miR-155-5p in salivary gland damage in SS, suggesting that miR-155-5p may serve to be a potential target for SS treatment.

\section{Acknowledgements}

Not applicable.

\section{Funding}

This study was supported by a grant from the Fundamental Research Business Expense of Universities in Heilongjiang Province (grant no. 2018-KYYWFMY-0060).

\section{Availability of data and materials}

The datasets used and/or analyzed during the current study are available from the corresponding author on reasonable request.

\section{Authors' contributions}

JLZ and HZZ designed the study and wrote the manuscript. LLZ and HS performed the experiments, confirmed the authenticity of all the raw data and conducted statistical analysis. All authors read and approved the final manuscript.

\section{Ethics approval and consent to participate}

The present study was approved by the Ethics Committee of Hongqi Hospital Affiliated to Mudanjiang Medical University (Mudanjiang, China).

\section{Patient consent for publication}

Not applicable.

\section{Competing interests}

The authors declare that they have no competing interests.

\section{References}

1. Baldini C, Talarico R, Tzioufas AG and Bombardieri S: Classification criteria for Sjogren's syndrome: A critical review. J Autoimmun 39: 9-14, 2012.

2. Reale M, D'Angelo C, Costantini E, Laus M, Moretti A and Croce A: MicroRNA in Sjögren's syndrome: Their potential roles in pathogenesis and diagnosis. J Immunol Res 2018: 7510174, 2018.

3. Ramos-Casals M, Tzioufas AG and Font J: Primary Sjögren's syndrome: New clinical and therapeutic concepts. Ann Rheum Dis 64: 347-354, 2005.

4. Jimenez SA and Piera-Velazquez S: Potential role of human-specific genes, human-specific microRNAs and human-specific non-coding regulatory RNAs in the pathogenesis of systemic sclerosis and Sjögren's syndrome. Autoimmun Rev 12: 1046-1051, 2013.

5. Saito M, Ota Y, Öhashi H, Dei Y, Shimoyama K, Suzuki D, Hayashi $\mathrm{H}$ and Ogawa N: CD40-CD40 ligand signal induces the intercellular adhesion molecule-1 expression through nuclear factor-kappa B p50 in cultured salivary gland epithelial cells from patients with Sjögren's syndrome. Mod Rheumatol 17: 45-53, 2007. 
6. Gottenberg JE, Cagnard N, Lucchesi C, Letourneur F, Mistou S, Lazure T, Jacques S, Ba N, Ittah M, Lepajolec C, et al: Activation of IFN pathways and plasmacytoid dendritic cell recruitment in target organs of primary Sjögren's syndrome. Proc Natl Acad Sci USA 103: 2770-2775, 2006.

7. Bushati N and Cohen SM: MicroRNA functions. Annu Rev Cell Dev Biol 23: 175-205, 2007.

8. Chen CZ, Li L, Lodish HF and Bartel DP: MicroRNAs modulate hematopoietic lineage differentiation. Science 303: 83-86, 2004.

9. Mestdagh P, Feys T, Bernard N, Guenther S, Chen C, Speleman F and Vandesompele J: High-throughput stem-loop RT-qPCR miRNA expression profiling using minute amounts of input RNA. Nucleic Acids Res 36: e143, 2008.

10. Wang F, Shan S, Huo Y, Xie Z, Fang Y, Qi Z, Chen F, Li Y and Sun B: miR-155-5p inhibits PDK1 and promotes autophagy via the mTOR pathway in cervical cancer. Int J Biochem Cell Biol 99: 91-99, 2018.

11. Elton TS, Selemon H, Elton SM and Parinandi NL: Regulation of the MIR155 host gene in physiological and pathological processes. Gene 532: 1-12, 2013.

12. Jiang $\mathrm{K}, \mathrm{Hu} \mathrm{J}$, Luo G, Song D, Zhang P, Zhu J and Sun F: miR-155-5p promotes oxalate- and calcium-induced kidney oxidative stress injury by suppressing MGP expression. Oxid Med Cell Longev 2020: 5863617, 2020.

13. Goncalves-Alves E, Saferding V, Schliehe C, Benson R, Kurowska-Stolarska M, Brunner JS, Puchner A, Podesser BK, Smolen JS, Redlich K, et al: MicroRNA-155 controls Thelper cell activation during viral infection. Front Immunol 10: 1367, 2019.

14. Vigorito E, Kohlhaas S, Lu D and Leyland R: miR-155: An ancient regulator of the immune system. Immunol Rev 253: 146-157, 2013

15. Tavasolian F, Abdollahi E, Rezaei R, Momtazi-Borojeni AA Henrotin Y and Sahebkar A: Altered expression of microRNAs in rheumatoid arthritis. J Cell Biochem 119: 478-487, 2018.

16. Cao W, Qian G, Luo W, Liu X, Pu Y, Hu G, Han L, Yuan L, A X and Deng D: miR-125b is downregulated in systemic lupus erythematosus patients and inhibits autophagy by targeting UVRAG. Biomed Pharmacother 99: 791-797, 2018.

17. Johansson A, Nyberg WA, Sjöstrand M, Moruzzi N, Bergman P, Khademi M, Andersson M, Piehl F, Berggren PO, Covacu R, et al: miR-31 regulates energy metabolism and is suppressed in Tcells from patients with Sjögren's syndrome. EurJImmunol 49:313-322, 2019.

18. Gourzi VC, Kapsogeorgou EK, Kyriakidis NC and Tzioufas AG: Study of microRNAs (miRNAs) that are predicted to targe the autoantigens Ro/SSA and La/SSB in primary Sjögren's syndrome. Clin Exp Immunol 182: 14-22, 2015.

19. Chen JQ, Zilahi E, Papp G, Sipka S and Zeher M: Simultaneously increased expression of microRNA-155 and suppressor of cytokine signaling 1 (SOCS1) gene in the peripheral blood mononuclear cells of patients with primary Sjögren's syndrome. Int J Rheum Dis 20: 609-613, 2017.

20. Wang X, Huang G, Mu J, Cong Z, Chen S, Fu D, Qi J and Li Z: Arrb2 promotes endothelial progenitor cell-mediated postischemic neovascularization. Theranostics 10:9899-9912,2020.

21. Chen G, Xie RG, Gao YJ, Xu ZZ, Zhao LX, Bang S, Berta T, Park CK, Lay M, Chen W and Ji RR: $\beta$-arrestin-2 regulates NMDA receptor function in spinal lamina II neurons and duration of persistent pain. Nat Commun 7: 12531, 2016.

22. Kallifatidis G, Smith DK, Morera DS, Gao J, Hennig MJ, Hoy JJ, Pearce RF, Dabke IR, Li J, Merseburger AS, et al: $\beta$-arrestins regulate stem cell-like phenotype and response to chemotherapy in bladder cancer. Mol Cancer Ther 18: 801-811, 2019.

23. Sharma D, Malik A, Lee E, Britton RA and Parameswaran N Gene dosage-dependent negative regulatory role of $\beta$-arrestin- 2 in polymicrobial infection-induced inflammation. Infect Immun 81: 3035-3044, 2013.

24. Zeng LX, Tao J, Liu HL, Tan SW, Yang YD, Peng XJ, Liu ZH, Jiang $\mathrm{J}$ and $\mathrm{Wu} \mathrm{B}$ : $\beta$-arrestin 2 encourages inflammation-induced epithelial apoptosis through ER stress/PUMA in colitis. Mucosal Immunol 8: 683-695, 2015.

25. Gaffal E, Jakobs M, Glodde N, Schröder R, Kostenis E and Tüting T: $\beta$-arrestin 2 inhibits proinflammatory chemokine production and attenuates contact allergic inflammation in the skin. J Invest Dermatol 134: 2131-2137, 2014

26. Jiang MP, Xu C, Guo YW, Luo QJ, Li L, Liu HL, Jiang J, Chen HX and Wei XQ: $\beta$-arrestin 2 attenuates lipopolysaccharide-induced liver injury via inhibition of TLR4/NF- $\mathrm{B}$ signaling pathway-mediated inflammation in mice. World $\mathrm{J}$ Gastroenterol 24: 216-225, 2018
27. Vakrakou AG, Polyzos A, Kapsogeorgou EK, Thanos D and Manoussakis MN: Impaired anti-inflammatory activity of PPAR $\gamma$ in the salivary epithelia of Sjögren's syndrome patients imposed by intrinsic NF- $\mathrm{kB}$ activation. J Autoimmun 86: 62-74, 2018

28. Sisto M, Barca A, Lofrumento DD and Lisi S: Downstream activation of $\mathrm{NF}-\kappa \mathrm{B}$ in the EDA-A1/EDAR signalling in Sjögren's syndrome and its regulation by the ubiquitin-editing enzyme A20. Clin Exp Immunol 184: 183-196, 2016.

29. National Research Council (US) Committee for the Update of the Guide for the Care and Use of Laboratory Animals: Guide for the care and use of laboratory animals. 8th edition. Washington (DC), National Academies Press (US), 2011.

30. Xin M, Liang H, Wang H, Wen D, Wang L, Zhao L, Sun M and Wang J: Mirt2 functions in synergy with miR-377 to participate in inflammatory pathophysiology of Sjögren's syndrome. Artif Cells Nanomed Biotechnol 47: 2473-2480, 2019.

31. Zhang C, Li Y, Zhang XY, Liu L, Tong HZ, Han TL, Li WD, Jin XL, Yin NB, Song T, et al: Therapeutic potential of human minor salivary gland epithelial progenitor cells in liver regeneration. Sci Rep 7: 12707, 2017.

32. Gao Y, Li M, Zhang X, Bai T, Chi G, Liu JY and Li Y: Isolation, culture and phenotypic characterization of human sweat gland epithelial cells. Int J Mol Med 34: 997-1003, 2014.

33. Livak KJ and Schmittgen TD: Analysis of relative gene expression data using real-time quantitative PCR and the 2(-Delta Delta C(T)) method. Methods 25: 402-408, 2001.

34. Brito-Zerón P, Baldini C, Bootsma H, Bowman SJ, Jonsson R, Mariette X, Sivils K, TheanderE, Tzioufas A and Ramos-Casals M: Sjogren syndrome. Nat Rev Dis Primers 2: 16047, 2016.

35. Mehta A and Baltimore D: MicroRNAs as regulatory elements in immune system logic. Nat Rev Immunol 16: 279-294, 2016.

36. Tahamtan A, Teymoori-Rad M, Nakstad B and Salimi V: Anti-inflammatory microRNAs and their potential for inflammatory diseases treatment. Front Immunol 9: 1377, 2018.

37. Ceppi M, Pereira PM, Dunand-Sauthier I, Barras E, Reith W, Santos MA andPierreP: MicroRNA-155 modulates the interleukin-1 signaling pathway in activated human monocyte-derived dendritic cells. Proc Natl Acad Sci USA 106: 2735-2740, 2009.

38. Kurowska-Stolarska M, Alivernini S, Ballantine LE, Asquith DL, Millar NL, Gilchrist DS, Reilly J, Ierna M, Fraser AR, Stolarski B, et al: MicroRNA-155 as a proinflammatory regulator in clinical and experimental arthritis. Proc Natl Acad Sci USA 108: 11193-11198, 2011

39. Milic V, Colic J, Cirkovic A, Stanojlovic S and Damjanov N Disease activity and damage in patients with primary Sjogren's syndrome: Prognostic value of salivary gland ultrasonography. PLoS One 14: e0226498, 2019.

40. Daniels TE, Silverman S Jr, Michalski JP, Greenspan JS, Sylvester RA and Talal N: The oral component of Sjögren's syndrome. Oral Surg Oral Med Oral Pathol 39: 875-885, 1975.

41. Cha S, Nagashima H, Brown VB, Peck AB and Humphreys-Beher MG: Two NOD Idd-associated intervals contribute synergistically to the development of autoimmune exocrinopathy (Sjögren's syndrome) on a healthy murine background. Arthritis Rheum 46: 1390-1398, 2002.

42. Li P, Yang Y, Jin Y, Zhao R, Dong C, Zheng W, Zhang T, $\mathrm{Li} \mathrm{J}$ and Gu Z: B7-H3 participates in human salivary gland epithelial cells apoptosis through $\mathrm{NF}-\kappa \mathrm{B}$ pathway in primary Sjögren's syndrome. J Transl Med 17: 268, 2019.

43. Baker OJ, Camden JM, Redman RS, Jones JE, Seye CI, Erb L and Weisman GA: Proinflammatory cytokines tumor necrosis factor-alpha and interferon-gamma alter tight junction structure and function in the rat parotid gland Par-C10 cell line. Am J Physiol Cell Physiol 295: C1191-C1201, 2008.

44. Manganelli P and Fietta P: Apoptosis and Sjögren syndrome. Semin Arthritis Rheum 33: 49-65, 2003.

45. Shi Y, Li K, Xu K and Liu QH: miR-155-5p accelerates cerebral ischemia-reperfusion injury via targeting DUSP14 by regulating $\mathrm{NF}-\kappa \mathrm{B}$ and MAPKs signaling pathways. Eur Rev Med Pharmacol Sci 24: 1408-1419, 2020.

46. Atreya I, Atreya R and Neurath MF: NF-kappaB in inflammatory bowel disease. J Intern Med 263: 591-596, 2008.

47. Roman-Blas JA and Jimenez SA: NF-kappaB as a potential therapeutic target in osteoarthritis and rheumatoid arthritis. Osteoarthritis Cartilage 14: 839-848, 2006.

48. Lisi S, Sisto M, Soleti R, Saponaro C, Scagliusi P, D'Amore M, Saccia M, Maffione AB and Mitolo V: Fcgamma receptors mediate internalization of anti-Ro and anti-La autoantibodies from Sjögren's syndrome and apoptosis in human salivary gland cell line A-253. J Oral Pathol Med 36: 511-523, 2007. 
49. Sisto M, Lisi S, Lofrumento DD, Ingravallo G, Maiorano E and D'Amore M: A failure of TNFAIP3 negative regulation maintains sustained NF- $\kappa$ B activation in Sjögren's syndrome. Histochem Cell Biol 135: 615-625, 2011.

50. Lisi S, Sisto M, Lofrumento DD and D'Amore M: Sjögren's syndrome autoantibodies provoke changes in gene expression profiles of inflammatory cytokines triggering a pathway involving TACE/NF-кB. Lab Invest 92: 615-624, 2012.

51. Wang X, Shaalan A, Liefers S, Coudenys J, Elewaut D, Proctor GB, Bootsma H, Kroese FGM and Pringle $\mathrm{S}$ : Dysregulation of NF-kB in glandular epithelial cells results in Sjögren's-like features. PLoS One 13: e0200212, 2018.

52. Sisto M, Lorusso L and Lisi S: TLR2 signals via NF- $\kappa B$ to drive IL-15 production in salivary gland epithelial cells derived from patients with primary Sjögren's syndrome. Clin Exp Med 17: 341-350, 2017.

53. Lawrence T: The nuclear factor NF-kappaB pathway in inflammation. Cold Spring Harb Perspect Biol 1: a001651, 2009.

54. Zhou Y, Song Y, Shaikh Z, Li H, Zhang H, Caudle Y, Zheng S, Yan $\mathrm{H}, \mathrm{Hu} \mathrm{D}$, Stuart $\mathrm{C}$ and Yin D: MicroRNA-155 attenuates late sepsis-induced cardiac dysfunction through JNK and $\beta$-arrestin 2. Oncotarget 8: 47317-47329, 2017.

55. Li P, Cook JA, Gilkeson GS, Luttrell LM, Wang L, Borg KT, Halushka PV and Fan H: Increased expression of beta-arrestin 1 and 2 in murine models of rheumatoid arthritis: Isoform specific regulation of inflammation. Mol Immunol 49: 64-74, 2011.
56. Hong $\mathrm{F}$, Zhang $\mathrm{Y}$, Cheng $\mathrm{W}$, Sun $\mathrm{X}$ and Wang J: $\beta$-arrestin-2 up-regulates toll-like receptor 2 signaling and inhibits apoptosis in human endometrial cancer heterotransplants in nude mice. BMC Cancer 19: 1035, 2019.

57. Li Y, Sun X, Zhang Y, Huang J, Hanley G, Ferslew KE, Peng Y and Yin D: Morphine promotes apoptosis via TLR2, and this is negatively regulated by beta-arrestin 2 . Biochem Biophys Res Commun 378: 857-861, 2009.

58. Trotta R, Chen L, Ciarlariello D, Josyula S, Mao C, Costinean S, Yu L, Butchar JP, Tridandapani S, Croce CM and Caligiuri MA: miR-155 regulates IFN- $\gamma$ production in natural killer cells. Blood 119: 3478-3485, 2012.

59. Yee D, Shah KM, Coles MC, Sharp TV and Lagos D: MicroRNA-155 induction via TNF- $\alpha$ and IFN- $\gamma$ suppresses expression of programmed death ligand-1 (PD-L1) in human primary cells. J Biol Chem 292: 20683-20693, 2017.

60. Kim JH, Jou I and Joe EH: Suppression of miR-155 expression in IFN- $\gamma$-treated astrocytes and microglia by DJ-1: A possible mechanism for maintaining SOCS1 expression. Exp Neurobiol 23: 148-154, 2014.

This work is licensed under a Creative Commons Attribution-NonCommercial-NoDerivatives 4.0 International (CC BY-NC-ND 4.0) License. 